\title{
Modelando Variáveis Meteorológicas com Funções Elementares
}

\author{
Merian O. Nascimento Maria Janete de M. Albuquerque \\ Rafaela A. Benjamim Arthur da C. Almeida \\ Faculdade de Matemática, UFPA, Campus de Castanhal \\ 68746-360, Castanhal, PA \\ E-mail: limamerian@gmail.com, janetecap@hotmail.com, rafaelab.ufpa@gmail.com, arthur@ufpa.br
}

\begin{abstract}
RESUMO
Situações, fatos da realidade ou fenômenos da natureza, podem ser trabalhados, transformados e apreciados como funções matemáticas através da modelagem matemática, possibilitando-nos assim, a mostrar que a matemática pode ser tratada, considerada e aplicada com muito mais eficácia em nosso cotidiano do que costuma ser.

Exemplos disso são os comportamentos das variáveis meteorológicas, tais como temperatura, pressão, umidade do ar, água precipitável, que por estarem diretamente relacionadas com o meio ambiente sofrem variação sazonal, de acordo com as estações do ano, apresentando assim comportamento aproximadamente periódico durante o ciclo anual ou diário [1].

Para as principais variáveis mencionadas acima, existem várias estações meteorológicas que fazem coletas desses dados em todo o mundo. A pesquisa em questão analisa especificamente algumas variáveis meteorológicas coletadas em Belém, capital do estado do Pará - Brasil América do Sul, as quais são coletadas através de um balão de radiossondagem solto todos os dias às $9 \mathrm{~h}$ (nove horas), horário local e às $12 \mathrm{~h}$ (doze horas) horário universal, no Aeroporto Internacional de Belém, sob a supervisão do comando da Aeronáutica. À medida que o balão sobe, o mesmo envia os dados diretamente para o posto de coleta através de rádio, podendo essas informações ser extraídas diretamente do site da Universidade de Wyoming: http://weather.uwyo.edu/upperair/sounding. Esse conjunto de dados, coletado em escala planetária, permite que se tenha uma amostra confiável do estado da atmosfera global a cada dia.

Este trabalho processou dados diários referentes aos anos de 2009-2011 para as variáveis temperatura na superfície e em alguns níveis especiais de pressão, pressão na superfície, água precipitável e altitude da base da nuvem. Vários gráficos e analises estatística foram usadas como ferramentas exploratórias dos dados em busca de compreensão de seu comportamento. Depois, em função dos resultados observados, analises estatísticas foram feitas e um modelo de função elementar, geralmente trigonométrica [2], dado o comportamento aproximadamente periódico dos dados, foi construído para que se ajustasse da melhor maneira aos dados.

Na Figura 1 observa-se o comportamento da variável água precipitável, estimada em $\mathrm{mm}$ a partir de dados da radiossondagem, durante o ano de 2009. Também observa-se claramente o seu caráter periódico diretamente relacionado com as estações do ano tal como são observadas na Amazônia: período chuvoso (janeiro a março), período seco (julho a setembro) e períodos de transição (maio a junho e outubro a dezembro).

Os resultados deste trabalho podem ter dois tipos de aplicações: encontrar funções que modelem de forma aproximada esses fenômenos e assim possam ser usados para fazer previsões e estimativa, embora de precisão e alcance limitados; nas atividades de ensino de matemática, como estimulo e incentivo para que estudantes se sintam mais interessados pela matemática e dessa forma se dediquem mais ao seu estudo e compreensão.
\end{abstract}




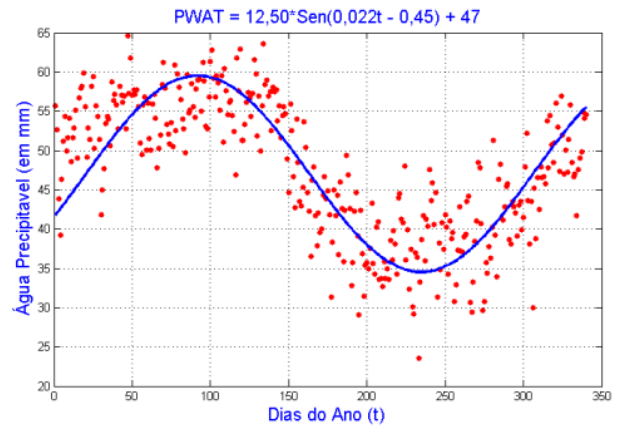

Figura 1: Dados de água precipitável e da senóide ajustada para sua modelagem

Palavras-chave: Modelagem matemática, variáveis atmosféricas, funções trigonométricas

\section{Referências}

[1] Donald C. Ahrens. Essentials of Meteorology: An Invitation to the Atmosphere. West Publishing Company. 1993.

[2] Roland E. Larson, Robert P. Hostetler, Bruce H. Edwards. Cálculo com Geometria Analítica. São Paulo: LTC Editora. 1998. 